\title{
Nifedipine in acute myocardial infarction: an assessment of left ventricular function, infarct size, and infarct expansion A double blind, randomised, placebo controlled trial
}

\author{
SIDNEY O GOTTLIEB, LEWIS C BECKER, JAMES L WEISS, EDWARD P SHAPIRO, \\ NISHA CHIBBER CHANDRA, JOHN T FLAHERTY, SHELDON H GOTTLIEB, \\ PAMELA OUYANG, E DAVID MELLITS, SUSAN N TOWNSEND, \\ MYRON L WEISFELDT, BERNADINE HEALY, GARY GERSTENBLITH
}

From the Division of Cardiology, Department of Medicine, The Johns Hopkins Hospital and Francis Scott Key Medical Center, Baltimore, Maryland, USA

SUMMARY The influence of nifedipine on left ventricular ejection fraction, infarct size, and infarct expansion was studied in a prospective, double blind, randomised, placebo controlled trial in 132 patients with low risk acute myocardial infarction of $<12$ hours duration, defined by an initial left ventricular ejection fraction $>35 \%$ and clinical Killip class of $\leqslant$ II. Sixty four patients were assigned to nifedipine $120 \mathrm{mg} /$ day and 68 to placebo. Treatment was started on average (SEM) 8.0 $(0 \cdot 2)$ hours after onset of pain and continued for six weeks. Gated blood pool scans, thallium scans, and cross sectional echocardiograms were performed before treatment and at 10 days. There were no significant differences between the two groups in age, sex, cardiac risk factors, or use of other medications. Mean (SEM) global left ventricular ejection fraction was not different before treatment (nifedipine group $53(2 \%)$, placebo group $55(2 \%)$ and did not differ at 10 days (nifedipine group $54(2 \%)$, placebo group $52(2 \%)$. There were also no differences in regional wall motion or regional ejection fractions. Thallium defects quantified by computer analysis were similar in both groups before treatment (nifedipine $7 \cdot 8(0 \cdot 7)$, placebo $7 \cdot 9(0.7)$ ) and at 10 days (nifedipine $5.3(0.7)$ placebo $5 \cdot 3(0.7)$ ). In the subgroup of patients with transmural infarction who had good quality echocardiograms and serial studies $(n=30)$, there was no difference in mean (SEM) baseline infarct segment lengths between the two groups (nifedipine 70 (4) mm, placebo 65 (4) $\mathrm{mm}$ ); however, the nifedipine group demonstrated no significant change in infarct segment length between the initial and 10 day studies $(+0.6(3) \mathrm{mm})$ while there was a significant increase in the infarct segment length in the placebo group $(+7 \cdot 8(4) \mathrm{mm})$. The infarct segment length increased by $\geqslant 1 \mathrm{~cm}$ in seven $(47 \%)$ placebo patients but in only one $(7 \%)$ nifedipine patient. The nifedipine group had a significant initial $10 \%$ decrease in mean arterial pressure whereas there was no change in the placebo group; this blood pressure difference persisted for 10 days.

Thus although the early administration of nifedipine has no detectable effect on clinical outcome and infarction size, it may reduce early infarct expansion via an afterload reduction mechanism in patients with transmural infarction. These initial results must be interpreted with caution and need to be confirmed in a larger trial.

Requests for reprints to Dr Sidney O Gottlieb, Cardiac Catheterization Laboratory, Francis Scott Key Medical Center, The Johns Hopkins Medical Institutions, 4940 Eastern Avenue, Baltimore, Maryland 21224, USA.

Accepted for publication 14 September 1987
Nifedipine is a potent dihydropyridine calcium antagonist which inhibits the calcium dependent excitation-contraction coupling processes in cardiac and smooth vascular muscle. ${ }^{1-3}$ Its efficacy is well documented in patients with stable ${ }^{45}$ and unstable 
angina, ${ }^{6-8}$ and there are theoretical reasons to suggest that it may also be beneficial in the treatment of acute myocardial infarction. These include a reduction of afterload mediated by peripheral vasodilatation, an increase in coronary flow via coronary vasodilator and antispasm effects, and the possibility of a direct protective effect on the myocardium. Animal studies have shown a reduction of infarct size with nifedipine given before and after coronary occlusion. ${ }^{-11}$ In addition, nifedipine may limit infarct expansion because left ventricular wall tension is an important determinant of expansion when the infarction is transmural..$^{12-14}$

Several controlled studies have examined the effect of the early administration of nifedipine in patients with acute myocardial infarction and have demonstrated no significant reduction in myocardial infarction size measured by creatine kinase release. ${ }^{15-17}$ One of these studies suggested that there may be an increased early mortality associated with nifedipine treatment ${ }^{15}$; however, the TRENT study which randomised 4491 patients showed no significant effect of lower dose nifedipine treatment ( $10 \mathrm{mg}$ four times daily) on mortality. ${ }^{17}$ None of these studies has shown beneficial effects of early nifedipine treatment on indices of infarction size or clinical outcome. The present study examines the effects of the early administration of a larger dose of nifedipine on global and regional left ventricular function, infarct size by quantitative scintigraphic techniques, and infarct expansion in patients with acute myocardial infarction.

\section{Patients and methods}

\section{PATIENT SELECTION}

We studied patients admitted to the coronary care units at the Johns Hopkins Hospital and Francis Scott Key Medical Center between the ages of 30 and 75 years with the clinical diagnosis of acute myocardial infarction of less than 12 hours duration. We selected only "low risk" Killip class I or II patients with an initial left ventricular ejection fraction by gated blood pool scan of $>35 \%$. Myocardial infarction was defined as typical ischaemic chest pain which lasted for at least $\mathbf{3 0}$ minutes with associated electrocardiographic changes of ST segment elevation $>1 \mathrm{~mm}$, new $Q$ waves, or persistent $T$ wave inversions in at least two leads. Enrolment did not require enzymatic confirmation of infarction because treatment had to be started within 12 hours of the onset of chest pain. Informed written consent, which had been approved by the hospitals' joint committee on clinical investigation, was obtained. Patients were excluded if they had a systolic pressure of $<100$ $\mathrm{mm} \mathrm{Hg}$, symptomatic cerebrovascular disease, $\mathbf{P}-\mathbf{R}$ interval $>0.24 \mathrm{~s}$, or higher degree atrioventricular block without a pacemaker in place, pulmonary oedema, cardiogenic shock, or if they were taking a calcium antagonist at the time of hospital admission.

\section{STUDY DESIGN}

After the patient had given informed consent to one of the study investigators, baseline thallium and gated blood pool scans were obtained in the coronary care unit with a portable gammacamera. These studies were performed by a 24 hour on-call team of experienced research nuclear cardiology technicians and were completed within 1.5-2 hours. After completion of the initial scans, the patients received, in a randomised double blind fashion, one capsule of the study drug, which was either nifedipine $10 \mathrm{mg}$ or a placebo capsule of identical appearance. Blood pressure was monitored every 10 minutes for one hour by a research nurse, and if the mean arterial pressure fell by $<10 \%$ and the systolic blood pressure was $>100$ $\mathrm{mm} \mathrm{Hg}$ a second study drug capsule was given. The pressure was similarly monitored for the next hour, and if the mean arterial pressure fell by $<10 \%$ and the systolic blood pressure remained $>100 \mathrm{~mm} \mathrm{Hg}$ a third capsule was administered with an additional hour of monitoring. Thus a maximum maintenance study drug dose of $10-30 \mathrm{mg}$ was established in each patient and this was then given every six hours for six weeks unless hypotension or any other side effect was noted.

Repeat gated blood pool scanning was performed immediately after the determination of the maintenance study drug dose and again at 10 days. Cross sectional echocardiograms were obtained within 24 hours of admission and again at 10 days in those patients who had technically interpretable initial echocardiographic studies. Twelve lead electrocardiograms were obtained daily while the patients were in the coronary care unit, and creatine kinase isoenzyme concentrations were measured every four hours for the first two days.

Routine coronary care unit management included oxygen by nasal cannula, intravenous lignocaine infusion for $24-48$ hours $(20-40 \mu \mathrm{g} / \mathrm{kg} / \mathrm{min})$, and full heparinisation ( 3000 unit bolus followed by 800 $1000 \mathrm{U} / \mathrm{h}$ infusion). Nitrates and $\beta$ blockers were not administered unless a patient experienced postinfarction ischaemic symptoms or if the patient was already on $\beta$ blockade. Other medications including morphine sulphate, digoxin, diuretics, oral antiarrhythmic agents, and sedatives were administered as needed.

GATED BLOOD POOL AND THALLIUM SCANNING Thallium scans were performed in the anterior, left anterior oblique $40^{\circ}$, left anterior oblique $60^{\circ}$, and 
lateral projections using thallium-201, 1.5-2.0 mCi. Images were obtained with a Technicare 420 mobile gammacamera interfaced to a VIP or Medical Data Systems computer. Thallium perfusion defects were measured by an objective thallium circumferential profile technique. ${ }^{18}$ Gated blood pool scans were performed in the anterior, left anterior oblique $40^{\circ}$, and lateral projections with red blood cells labelled in vivo with $25-30 \mathrm{mCi}$ technetium-99m with the same mobile camera. Global and regional ejection fractions were calculated by standard Medical Data Systems programs. The left ventricular volumes, stroke volume, and cardiac outputs were calculated by a count-based method developed at the Johns Hopkins Hospital. ${ }^{19}$ The gated blood pool images were separated into infarct and non-infarct zones by electrocardiographic correlation and by the assessment of regional wall motion abnormalities. A regional ejection fraction was then calculated for each zone from the mean of the adjacent $22.5^{\circ}$ pre-shaped sectors overlying the left ventricle, excluding the upper medial quadrant. Once they had been defined on the initial study, the same sectors were used to calculate regional ejection fractions for infarct and non-infarct zones on serial studies. The gated blood pool and thallium scans were interpreted blindly without knowledge of the study assignment.

\section{CROSS SECTIONAL ECHOCARDIOGRAPHY}

Serial cross sectional echocardiography was performed on days 1 and 10. Particular attention was given to obtaining a good cross sectional view at the level of the papillary muscles. The serial studies were quantitatively analysed blindly by a trained technician and then reviewed blindly by an investigator (JLW). Endocardial anterior and posterior segment lengths from cross sectional end diastolic frames at the level of the papillary muscles were measured in triplicate with a computer-aided contouring system and averaged by previously published methods. ${ }^{13}$ The anterior and posterior segment lengths were measured with the papillary muscles as landmarks, ${ }^{13}$ and the infarct segment was identified by electrocardiographic correlation. The intraobserver variability of this technique in our laboratory was $<5 \%{ }^{13}$ Because infarct expansion occurs only with transmural infarction, ${ }^{12-14}$ only patients with transmural infarction were included in the expansion analysis.

\section{OUTCOME VARIABLES}

The primary outcome variables for this study were global and regional left ventricular function, infarct size, and echocardiographic infarct expansion on the initial and 10 day studies. The clinical outcomes of death, recurrent infarction defined as chest pain lasting longer than 30 minutes with new electrocar- diographic changes and re-elevation of creatine kinase concentrations to greater than twice normal, recurrent ischaemia, and the need for coronary artery bypass surgery to control ischaemic symptoms were also examined, although the study population was not large enough to detect even large mortality differences. The calculated sample size of this study was sufficient to detect an approximate $50 \%$ difference in combined clinical outcomes (death, recurrent infarction, bypass surgery for recurrent angina symptoms) with a power of $0 \cdot 7$.

\section{DATA ANALYSIS}

Continuous variables were analysed by paired and non-paired $t$ tests as appropriate. Categorical data were examined by contingency-table analysis by the $\chi^{2}$ test. The proportion of patients in each study arm who experienced individual and combined clinical outcomes and the time-dependence of these outcomes were analysed by Kaplan-Meier actuarial curves, which were compared by a log-rank test with a two-tailed significance level. ${ }^{20}$ Repeated measures analysis of variance was used to compare the blood pressures in the two groups over time. The gated blood pool scan, thallium scan, and echocardiographic data were interpreted blindly without knowledge of study drug assignment or clinical course. Data are presented as mean (SE). The analyses include all patients originally assigned to each treatment arm, according to the intention to treat principle.

\section{Results}

A total of 132 patients were randomised: 64 were assigned to nifedipine and 68 to placebo. Table 1 shows the clinical characteristics of the study population. The patients were 33 to 75 years old and $67 \%$ were men. The mean time from the onset of chest pain to the start of treatment with the study drug was $8.0(0.2)$ hours for all patients. There were no significant baseline differences in the distribution of cardiovascular risk factors including previous myocardial infarction, treatment with other antiischaemic agents, initial Killip class, location of myocardial infarction, presence of non-transmural or transmural infarctions, size of the initial thallium defect, or initial left ventricular ejection fraction by gated blood pool scan performed before treatment.

\section{HAEMODYNAMIC RESPONSE TO STUDY DRUG}

The figure shows the mean arterial blood pressure response to the first maintenance study drug dose after completion of dose titration. The mean dose of nifedipine in the group randomised to nifedipine was $105 \mathrm{mg} /$ day: 39 patients received $120 \mathrm{mg} /$ day, 19 
Table 1 Comparison of baseline characteristics of patients in the nifedipine and placebo study groups $\star$

\begin{tabular}{lll}
\hline Characteristics & $\begin{array}{c}\text { Nifedipine } \\
(n=64)\end{array}$ & $\begin{array}{c}\text { Placebo } \\
(n=68)\end{array}$ \\
\hline Sex (male/female) (n) & $45 / 19$ & $44 / 24$ \\
Diabetes mellitus (n) & 8 & 12 \\
Current smoking (n) & 43 & 48 \\
Hypertension (n) & 32 & 39 \\
Previous MI (n) & 14 & 10 \\
Previous angina (n) & 37 & 35 \\
Killip class (n): O-I & 43 & 47 \\
& 21 & 21 \\
No MI (n) & 6 & 7 \\
Anterior/inferoposterior MI (n) & $24 / 34$ & $18 / 43$ \\
Transmural/non-transmural MI (n) & $39 / 19$ & $47 / 14$ \\
Nitrates (oral or topical) (n) & 34 & 32 \\
$\beta$ blockers (n) & 25 & 24 \\
Digoxin (n) & 8 & 6 \\
Antiplatelet agents (n) & 5 & 8 \\
Oral antiarrhythmic agents (n) & 4 & 5 \\
Age (years) (mean (SEM)) & $58(1)$ & $57(1 \cdot 2)$ \\
Onset of pain to treatment (mean & $8 \cdot 3(0 \cdot 2)$ & $7 \cdot 7(0 \cdot 2)$ \\
(SEM)) & & \\
Baseline LVEF (\%) (mean (SEM)) & $53(2)$ & $55(2)$ \\
Baseline thallium score (mean (SEM)) & $7 \cdot 8(0 \cdot 7)$ & $7 \cdot 9(0 \cdot 7)$ \\
\hline
\end{tabular}

*There is no significant difference between the two groups for any characteristic listed. MI, myocardial infarction; LVEF, left ventricular ejection fraction. Computer units for thallium defect score.

received $80 \mathrm{mg} /$ day, and six patients received $40 \mathrm{mg} /$ day. The initial mean arterial pressures before treatment with the study drug did not differ (nifedipine 100 (2), placebo 102 (2) $\mathrm{mm} \mathrm{Hg}$ ) (NS). After the study drug had been given to patients the mean arterial pressure decreased by $10 \%$ in the nifedipine group with a peak effect noted at $\mathbf{4 0}$ minutes, while the placebo group demonstrated no significant change $(p<0.001$ for difference between two groups). There was a minimal initial increase in the heart rate (mean of 3.0 beats per minute) in the nifedipine group, while the placebo group showed no significant change.

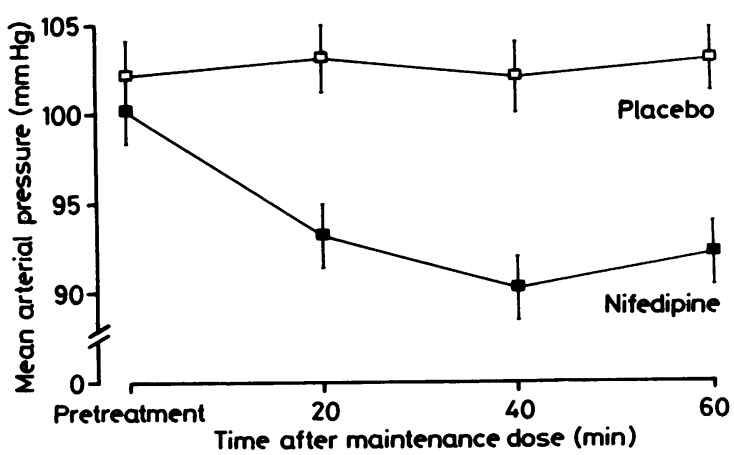

Figure The response of the mean arterial pressure to the maintenance dose of study drug. The mean arterial pressure decreased by $10 \%$ in the nifedipine group with a peak effect noted at $\mathbf{4 0}$ minutes, whereas there was no significant change in the placebo group ( $p<0.001$ for difference between the two groups). Data are mean (SEM).

\section{CLINICAL OUTCOMES}

Table 2 shows the clinical outcomes over the six week $C$ study period. Eight patients (four nifedipine, four $\vec{F}$ placebo) were withdrawn from the study because of side effects. The side effects in the nifedipine group were hypotension in three and dizziness in one patient. One placebo patient was withdrawn because of hypotension and three because of dizziness and other non-specific complaints attributed to the study is drug. Two other patients assigned to nifedipine and $\overrightarrow{0}$ four assigned to placebo withdrew themselves prematurely from the study. The analyses of the $\vec{\omega}$ clinical outcomes include all patients who were originally assigned to each treatment arm. Six nifedipine and seven placebo patients demonstrated no subsequent enzymatic evidence of myocardial infarction but were included in the analyses. There was no difference in the peak creatine kinase concen- $O$ trations between the nifedipine (1383 (150) IU) and $\rightarrow$ the placebo (1626 (152)) groups. Four patients in $\rightarrow$ each treatment arm died within six weeks $(6 \%$ overall mortality), and six nifedipine and seven placebo patients experienced recurrent myocardial infarc- $\infty$ tion. Five nifedipine and two placebo patients underwent coronary artery bypass surgery within six weeks for persistent post-infarction angina. Thus $23 \%$ of the nifedipine patients and $19 \%$ of the placebo patients experienced either death, reinfarction, or bypass surgery for symptoms at six weeks, and there was no significant group difference for the $\overrightarrow{\vec{O}}$ cumulative time dependent probability of experienc- $\exists$ ing any of these outcomes (Kaplan-Meier analysis). In order to detect a statistically significant difference of this magnitude with an alpha level of 0.05 and a power of 0.8 over 1400 patients would be required in each arm of the study.

\section{LEFT VENTRICULAR FUNCTION}

Table 3 shows the global and regional left ventricular function data. There is no significant difference in $ᄋ$ baseline global ejection fractions between the $D$ nifedipine (53 (2)\%) and placebo (55 (2)\%) groups. There are also no differences in the immediate post- $N$

Table 2 Clinical outcomes during six week study period: comparison of nifedipine and placebo groups $\star$

\begin{tabular}{|c|c|c|}
\hline & $\begin{array}{l}\text { Nifedipine } \\
(n=64)\end{array}$ & $\begin{array}{l}\text { Placebo } \\
(n=68)\end{array}$ \\
\hline $\begin{array}{l}\text { Death } \\
\text { Recurrent infarction } \\
\text { Bypass surgery for symptoms } \\
\text { Side effects requiring } \\
\text { withdrawal from study } \\
\text { Study withdrawals because of } \\
\text { non-compliance }\end{array}$ & $\begin{array}{l}4 \\
6 \\
5 \\
4 \\
2\end{array}$ & $\begin{array}{l}4 \\
7 \\
2 \\
4 \\
4\end{array}$ \\
\hline
\end{tabular}

*There is no significant difference between the two groups for any of the variables listed. 


\section{Nifedipine in acute myocardial infarction}

treatment (nifedipine 54 (2)\%, placebo $54(2) \%$ ) or 10 day (nifedipine 54 (2)\%, placebo $52(2) \%$ ) studies. The present sample size is sufficient to detect a $10 \%$ difference (that is between a $50 \%$ and a $55 \%$ ejection fraction) in the mean ejection fraction between the two study groups with an alpha level of 0.05 and power of 0.7 . When analysed as paired data, neither group showed a statistically significant change in ejection fraction between the initial and 10 day scans. Since patients with low initial ejection fractions tend to show improvement with time while those with high initial values tend to demonstrate a reduction as the high initial sympathetic tone decreases, ${ }^{21}$ the change in ejection fraction was also analysed separately in the subsets of nifedipine and placebo patients with an initial ejection fraction $\leqslant 50 \%$ and in those with an initial ejection fraction of $>50 \%$. No nifedipine effect was demonstrated as there was a similar improvement over the 10 day period in patients with a low initial ejection fraction, and a similar decline in global ejection fraction in the subset with a high initial ejection fraction. In the subgroup of patients who received early treatment ( $<6$ hours from pain onset) there is also no significant difference in $\mathbf{1 0}$ day global ejection fraction between the nifedipine and placebo patients. Initial and day 10 cardiac output and ventricular volumes also were not significantly different in the nifedipine and placebo groups (table 3). The pretreatment

Table 3 Comparison of resting global and regional left ventricular ejection fractions and calculated cardiac volumes and cardiac outputs in nifedipine and placebo groups*

\begin{tabular}{|c|c|c|}
\hline & $\begin{array}{l}\text { Nifedipine } \\
(n=64)\end{array}$ & $\begin{array}{l}\text { Placebo } \\
(n=68)\end{array}$ \\
\hline \multicolumn{3}{|l|}{ Global LVEF: } \\
\hline $\begin{array}{l}\text { Baseline } \\
\text { Post drug } \\
10 \text { day }\end{array}$ & $\begin{array}{l}53(2) \\
54(2) \\
54(2)\end{array}$ & $\begin{array}{l}55(2) \\
54(2) \\
52(2)\end{array}$ \\
\hline \multicolumn{3}{|l|}{ Regional LVEF: } \\
\hline $\begin{array}{l}\text { Baseline } \\
\text { Post drug } \\
10 \text { day }\end{array}$ & $\begin{array}{l}33(2) \\
34(2) \\
41(2)\end{array}$ & $\begin{array}{l}35(2) \\
36(2) \\
41(2)\end{array}$ \\
\hline \multicolumn{3}{|l|}{$\begin{array}{l}10 \text { day } \\
\text { non-infarct zone: }\end{array}$} \\
\hline $\begin{array}{l}\text { Baseline } \\
\text { Post drug } \\
10 \text { day }\end{array}$ & $\begin{array}{l}61(1 \cdot 3) \\
60(2) \\
59(2)\end{array}$ & $\begin{array}{l}64(1 \cdot 5) \\
60(2) \\
60(2)\end{array}$ \\
\hline \multicolumn{3}{|l|}{ End diastolic volume $(\mathrm{ml})$ : } \\
\hline $\begin{array}{l}\text { Baseline } \\
\text { Post drug } \\
10 \text { day }\end{array}$ & $\begin{array}{l}155(5) \\
157(6) \\
146(5)\end{array}$ & $\begin{array}{l}161(6) \\
166(7) \\
157(5)\end{array}$ \\
\hline \multicolumn{3}{|l|}{$\begin{array}{l}10 \text { day } \\
\text { End systolic volume (ml): }\end{array}$} \\
\hline $\begin{array}{l}\text { Baseline } \\
\text { Post drug } \\
10 \text { day }\end{array}$ & $\begin{array}{l}76(4) \\
76(5) \\
68(4)\end{array}$ & $\begin{array}{l}74(4) \\
78(5) \\
78(4)\end{array}$ \\
\hline \multicolumn{3}{|l|}{ Cardiac output (1/min): } \\
\hline $\begin{array}{l}\text { Baseline } \\
\text { Post drug } \\
10 \text { day }\end{array}$ & $\begin{array}{l}6 \cdot 1(0 \cdot 3) \\
6 \cdot 1(0 \cdot 3) \\
5 \cdot 5(0-2)\end{array}$ & $\begin{array}{l}6.5(0-2) \\
6.4(0-3) \\
5.5(0-2)\end{array}$ \\
\hline
\end{tabular}

*There is no significant difference between the two groups for any variables listed. LVEF, left ventricular ejection fraction. infarct zone regional ejection fractions were 33 (2)\% in the nifedipine and 35 (2)\% in the placebo groups (NS). The regional ejection fractions of the noninfarct zone were $61(1.3) \%$ in the nifedipine and 64 $(1.5) \%$ in the placebo groups (NS). At 10 days the ejection fractions of the infarct zones were significantly improved in both the nifedipine $(+6(2) \%)$ and placebo groups (+7.5 (2)\%) and there was no difference between the two groups. In contrast, the regional non-infarct zone ejection fractions were minimally reduced in both the nifedipine $(-3$ $(1 \cdot 7) \%)$ and placebo groups $(-4(1 \cdot 6) \%$, table 3$)$. Thus the net change in global ejection fraction over the 10 day period is determined by opposite trendsan increase in the infarct zones and a decrease in the non-infarct zones.

\section{THALLIUM SCINTIGRAM RESULTS}

The initial and 10 day thallium perfusion images were analysed quantitatively by methods described elsewhere. ${ }^{18}$ The initial pretreatment thallium scores in the nifedipine (7.8 (0.7) units) and placebo (7.9 (0.7) units) groups did not differ. The day 10 thallium score was lower in both groups and also did not differ significantly (nifedipine 5.3 (0.7), placebo $5.3(0.7)$ ). Thus quantitative analysis of myocardial infarction size by serial (at the start of the trial and 10 days later) thallium scintigraphy showed no nifedipine effect.

\section{INFARCT EXPANSION: CROSS SECTIONAL \\ ECHOCARDIOGRAPHIC ANALYSES}

Serial cross sectional echocardiographic studies were performed on days 1 and 10 in those patients with transmural infarctions who had not reached an unfavourable outcome in the interim and in whom technically good quality images could be obtained for quantitative contouring and analysis. Of the 132 patients who were randomised, 86 had transmural infarctions and 44 of these had good quality echocardiographic studies during the first two days that were technically adequate for detailed contouring. Fourteen of these patients were unavailable for serial studies. The technical quality of the studies was judged by a technician who was unaware of the study drug assignment.

Table 4 shows the baseline clinical characteristics of the $\mathbf{3 0}$ patients in the echocardiographic subset. Fifteen patients were assigned to nifedipine and 15 to placebo. There is no significant difference between the two groups with regard to age, sex, location of infarction, other medications, baseline ejection fraction, thallium score, and systolic blood pressure. There is also no significant difference in the initial infarct segment lengths between the nifedipine (70 (4) $\mathrm{mm}$ ) and placebo (65 (4) $\mathrm{mm}$ ) groups. None the 
Table 4 Baseline characteristics of subset of patients with transmural infarctions and serial echocardiographic studies: comparison of patients in the nifedipine and placebo groups

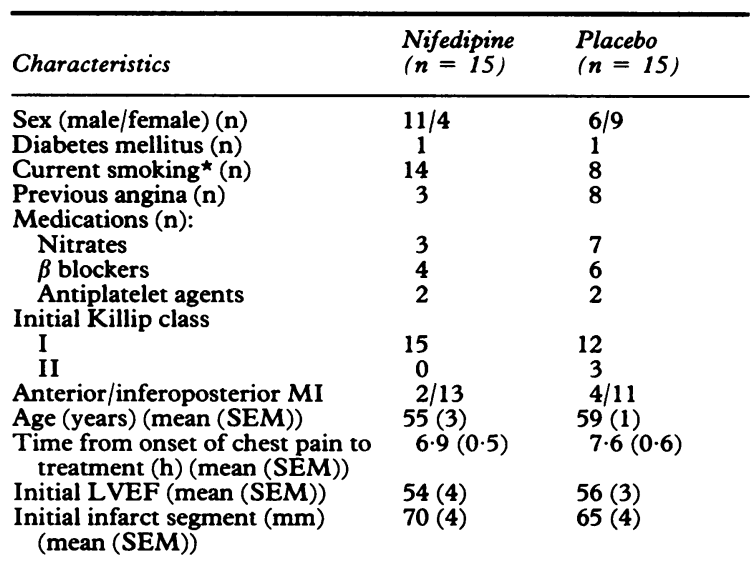

$\star(p<0.05)$. There is no significant difference between the groups for any other characteristic listed. MI, myocardial infarction; LVEF, left ventricular ejection fraction.

less, there was a significant increase in infarct segment length $(+7.8(4) \mathrm{mm}, \mathrm{p}<0.05)$ in the placebo group between the studies on day 1 and on day 10, and none in the nifedipine group ( +0.6 (3) $\mathrm{mm}$, $p=N S)$. The infarct segment length increased by $\geqslant 1 \mathrm{~cm}$ in seven patients assigned to placebo but in only one assigned to nifedipine $(p<0.05)$. Both groups showed a similar increase in the non-infarct segment lengths (nifedipine 9 (4) $\mathrm{mm}$, placebo 8 (4) $\mathrm{mm}, \mathrm{p}=\mathrm{NS})$. As in the overall study population, the nifedipine group in this echocardiographic analysis showed a significant fall in systolic blood pressure $\mathbf{4 0}$ minutes after receiving the initial maintenance dose of the study drug $(-8.1$ (1) $\mathrm{mm} \mathrm{Hg}$, $p=0.04$ ), while the placebo group did not. This difference between the groups persisted over 10 days ( $p<0.05$ by repeated measures analysis), and the 10 day mean arterial pressures were 81 (1) $\mathrm{mm} \mathrm{Hg}$ in the nifedipine group and 87.3 (1) $\mathrm{mm} \mathrm{Hg}$ in the placebo group $(p=0.02)$. The cardiac volumes measured by gated blood pool scans in this subgroup were not significantly different in the two treatment groups. The non-infarct segment lengths increased similarly in both groups and this may have masked differences caused by changes in infarct segments.

\section{Discussion}

The present study shows that nifedipine given to patients with acute myocardial infarction within 12 hours of the onset of pain has no detectable effect on global or regional left ventricular function or myocardial infarct size by thallium scintigraphy. The power of this individual study to detect a significant difference in mortality and reinfarction is quite low, but the present findings are consistent with other published reports of early nifedipine treatment in acute infarction. ${ }^{15-17}$ The echocardiographic findings in a subset of patients with transmural infarction, however, suggest that early nifedipine treatment in a dose sufficient to lower mean arterial blood pressure by approximately $10 \%$ may decrease the occurrence and extent of infarct zone expansion. The clinical significance of this observation is unclear, however, and these data must be interpreted with caution as they apply to a relatively small and selected subset of the study population.

Theoretical considerations and studies in animal models suggesting that calcium antagonist treatment may limit infarct size have prompted considerable interest in the role of these agents in patients with an acute myocardial infarction. ${ }^{15-17}$ These drugs reverse coronary vasoconstriction, which may accompany an infarction $^{22}$ and may be the proximate cause of coronary artery occlusion in some patient subsets. ${ }^{23}$ They may also improve myocardial oxygen supply and decrease oxygen demand by increasing collateral flow and decreasing afterload via their vasodilatory effects on the coronary and peripheral circulation. ${ }^{24}$ Although treatment with calcium antagonists reduced infarct size in some animal studies, ${ }^{9-11}$ the effect was studied only when the agent was given before or within one hour of the onset of ischaemia. In addition, the effect may be dependent on a collateral network capable of delivering the agent to the ischaemic area itself since the benefit in dogs, which have well developed collaterals, is considerably greater than that in baboons, ${ }^{25}$ which do not.

There have been four other randomised controlled studies examining the effect of nifedipine in patients with threatened or actual acute infarction. ${ }^{15-17} 26$ These have focused on the enzymatic determination of infarct size and on the clinical course. A Norwegian trial showed no significant difference in creatine kinase release in the nifedipine and placebo groups. ${ }^{16}$ Another study also reported no significant difference in infarct size estimated by creatine kinase release, but reported a higher two week mortality in the nifedipine treatment group that was not present at six months. ${ }^{15}$ These trials were also too small to detect differences in major clinical outcomes such as mortality; however, the largest trial of nifedipine in suspected or confirmed acute infarction (the TRENT study) found that a daily dose of $\mathbf{4 0} \mathrm{mg}$ of nifedipine had no significant effect on one month mortality in 4491 randomised patients. ${ }^{17}$

The lack of a reduction in infarct size or of a significant difference in major clinical outcomes in all of these trials may be related to several factors. 
Although nifedipine is a potent coronary vasodilator, coronary vasoconstriction may have a relatively small role in most infarct patients. Even if spasm is an important initiating event, the superimposition of thrombus may prevent reperfusion with antispasm treatment alone. ${ }^{27}$ In addition, any direct protective effect is dependent on the extent of collateral supply to the infarcted region, which is usually limited in patients with initial transmural infarctions. ${ }^{28}$ Finally, reperfusion studies have indicated that strategies designed to salvage myocardium must be started immediately after the onset of ischaemia. ${ }^{29-31}$ The mean time from the development of chest pain to treatment in these trials ranged from 4.6 to 8 hours, which is probably too long to achieve significant myocardial salvage.

These negative results with calcium antagonist treatment in non-selected acute infarction patients (most of whom had completed $Q$ wave infarctions) contrast with other data supporting the efficacy of anti-ischaemic drugs for selected subsets of high risk patients in whom the potential for recurrent ischaemia after infarction is increased. The beneficial effect of calcium antagonist treatment in reducing early reinfarctions in patients with non-Q-wave infarctions, ${ }^{32}$ the benefit of nifedipine for patients with post-infarction angina, ${ }^{833}$ and the reduction of cardiac mortality by $\beta$ blockers, most notably in high risk subgroups, ${ }^{34-36}$ collectively suggest that nonthrombolytic anti-ischaemic treatment is likely to be beneficial only in patients with high potential for recurrent ischaemia, such as non-Q-wave infarction patients.

The serial echocardiographic findings in the subset of patients with transmural infarction suggest that the effect of nifedipine in reducing afterload may limit the expansion of the infarct zone during the ten days after an infarction. Although early expansion of the infarct is associated with an early increase in morbidity and mortality and the late development of left ventricular aneurysms, ${ }^{12-14}$ the number of patients in the present trial with infarct expansion is too small for a difference in clinical outcome to be detected even if one were present. In addition, our population included many patients with inferior infarctions, in whom the clinical significance of infarct expansion is uncertain. A recent controlled study showing that intravenous glyceryl trinitrate and early intra-aortic balloon counterpulsation in patients with extensive anterior infarctions and low ejection fraction reduce the expansion into the noninfarcted area also suggests that afterload reduction may favourably influence the remodelling of the ventricular cavity that occurs after infarction. ${ }^{37}$ Other agents which reduce afterload have been reported to have a favourable effect on infarct expansion includ- ing glyceryl trinitrate in humans ${ }^{38}$ and captopril in rats, ${ }^{39}$ suggesting that the afterload reduction itself may be the mechanism for this effect.

The time course of myocardial necrosis in human beings seems to be rapid, and interventions designed to limit infarct size should be started as early as possible. ${ }^{40}$ The mean time between the onset of chest pain and treatment in this study was $8(0 \cdot 2)$ hours, primarily because the study design required baseline thallium and gated blood pool scans before the start of treatment in order to assess the effect of the agent on left ventricular function and the thallium scintigraphic definition of infarct size relative to the region at risk. The additional delay introduced by these baseline studies may have limited our ability to demonstrate a treatment benefit. Nevertheless, the analysis of the patient subset that received treatment within six hours, as well as previous studies ${ }^{15-17}$ in which nifedipine treatment was initiated 4-6 hours after the onset of pain, also showed no benefit of nifedipine. At the present time, the collective results of the randomised nifedipine trials demonstrate no significant clinical benefit of nifedipine given in low or high doses.

Computational assistance was provided by CLINFO, sponsored by a grant from the National Institutes of Health. This study was supported by a Specialized Center of Research for Ischemic Heart Disease grant from the National Institutes of Health.

\section{References}

1 Fleckenstein A. Specific pharmacology of calcium in myocardium, cardiac pacemakers, and vascular smooth muscle. Annu Rev Pharmacol Toxicol 1977; 17:149-66.

2 Adelstein RS, Hathaway DR. Role of calcium and cyclic adenosine $3^{\prime}: 5^{\prime}$ monophosphate in regulating smooth muscle contraction: mechanisms of excitationcontraction coupling in smooth muscle. Am J Cardiol 1979;44:783-7.

3 Henry PD. Comparative pharmacology of calcium antagonists: nifedipine, verapamil; correlation with plasma drug concentrations. Am J Cardiol 1980; 46:1047-58.

4 Moskowitz RM, Piccini PA, Nacarelli GV, Zelis R. Nifedipine therapy for stable angina pectoris: preliminary results of effects on angina frequency and treadmill exercise response. Am $J$ Cardiol 1979;44:811-6.

5 Mueller HS, Chahine RA. Interim report of multicenter double-blind, placebo-controlled studies of nifedipine in chronic stable angina. $\mathrm{Am} \mathrm{J} \mathrm{Med}$ $1981 ; 71: 645-55$.

6 Hugenholtz PG, Michels HR, Serruys PW, Brower RW. Nifedipine in the treatment of unstable angina, coronary spasm and myocardial ischemia. Am J Cardiol 1981;47:163-73. 
7 Muller JE, Turi ZG, Pearle DL, et al. Nifedipine and conventional therapy for unstable angina pectoris: a randomized, double-blind comparison. Circulation 1984;69:729-39.

8 Gerstenblith G, Ouyang P, Achuff SC, et al. Nifedipine in unstable angina - a double-blind, randomized trial. N Engl J Med 1982;306:885-9.

9 Melin JA, Becker LC, Hutchins GM. Protective effect of early and late treatment with nifedipine during myocardial infarction in the conscious dog. Circulation 1984;69:131-41.

10 Selwyn AP, Welman E, Fox K, Horlock P, Pratt T, Klein $M$. The effects of nifedipine on acute experimental myocardial ischemia and infarction in dogs. Circ Res 1979;44:16-21.

11 Nayler WG, Ferrari R, Williams A. Protective effect of pretreatment with verapamil, nifedipine, and propranolol on mitochondrial function in the ischemic and reperfused myocardium. Am J Cardiol 1980;46:242-8.

12 Eaton LW, Weiss JL, Bulkley BH, Garrison JB, Weisfeldt ML. Regional cardiac dilatation after acute myocardial infarction. Recognition by two-dimensional echocardiography. N Engl J Med 1979;300: 57-62.

13 Erlebacher JA, Weiss JL, Eaton LW, Kallman CH, Weisfeldt ML, Bulkley BH. Late effects of acute infarct dilation on heart size: a two dimensional echocardiographic study. Am J Cardiol 1982; 49:1120-6.

14 Erlebacher JA, Weiss JL, Weisfeldt ML, Bulkley BH. Early dilation of the infarcted segment in acute transmural myocardial infarction: role of infarct expansion in acute left ventricular enlargement. $J \mathrm{Am}$ Coll Cardiol 1984;4:201-8.

15 Muller JE, Morrison J, Stone PH, et al. Nifedipine therapy for patients with threatened and acute myocardial infarction: a randomized, double-blind, placebo-controlled comparison. Circulation 1984; 69:740-7.

16 Sirnes PA, Overskeid K, Pederson TR, et al. Evolution of infarct size during the early use of nifedipine in patients with acute myocardial infarction: the Norwegian Nifedipine Multicenter Trial. Circulation 1984;70:638-44.

17 Wilcox RG, Hampton JR, Banks DC, et al. Trial of early nifedipine in acute myocardial infarction: the Trent study. Br Med J 1986;293:1204-8.

18 Burow RD, Pond M, Schaeffer AW, Becker LC. Circumferential profiles: a method for computer analysis of thallium-201 myocardial perfusion images. J Nucl Med 1979;20:771-7.

19 Links JM, Becker LC, Shindledecker G, et al. Measurement of absolute left ventricular volume from gated blood pool studies. Circulation 1982; 65:82-6.

20 Kaplan EL, Meier P. Nonparametric estimation from incomplete observations. J Am Stat Assoc 1958; 53:457-81.

21 Stack RS, Phillips HR, Grierson DS, et al. Functional improvement of jeopardized myocardium following intracoronary streptokinase infusion in acute myocardial infarction. J Clin Invest 1983;72:84-95.

22 Oliva PB, Breckinridge JC. Arteriographic evidence of coronary arterial spasm in acute myocardial infarc- tion. Circulation 1977;56:366-74.

23 Maseri A, L'Abbate A, Bardoldi G, et al. Coronary $C$ vasospasm as possible cause of myocardial infarction: $\vec{\Rightarrow}$ a conclusion derived from the study of "preinfarc- $\stackrel{\rho}{\stackrel{9}{ }}$ tion" angina. N Engl J Med 1978;299:1271-7.

24 Engel H-J, Lichtlen PR. Beneficial enhancement of coronary blood flow by nifedipine. Am J Med 1981; $\stackrel{\bar{\omega}}{\circ}$ 71:658-63.

25 Geary GG, Smith GT, Suehiro GT, McNamara JJ. Failure of nifedipine therapy to reduce myocardial $\odot$ infarct size in the baboon. Am J Cardiol 1982;49: $\overrightarrow{0}$ 331-8.

26 Branagan J, Walsh K, Kelly P, Collins WC, $\vec{\omega}$ McCahherty D, Walsh MJ. Effect of early treatment $\stackrel{?}{?}$ with nifedipine in suspected acute myocardial infarction. Eur Heart $J$ 1986;7:859-65.

27 Vincent GM, Anderson JL, Marshall HW. Coronary spasm producing coronary thrombosis and myocardial infarction. N Engl J Med 1983;309:220-3.

28 Nitzberg WD, Nath HP, Rogers WJ, et al. Collateral 응 flow in patients with acute myocardial infarction. $\mathrm{Am}_{-}$ $J$ Cardiol 1985;56:729-36.

29 Kennedy JW, Ritchie JL, David KB, Fritz JK. Western Washington randomized trial of intracoronary streptokinase in acute myocardial infarction. N Engl J Med $\vec{\varnothing}$ 1983;309:1477-82.

30 GISSI Study Group. Effectiveness of intravenous thrombolytic therapy in acute myocardial infarction. Lancet 1986;i:397-401.

31 ISAM Study Group. A prospective trial of intravenous streptokinase in acute myocardial infarction (ISAM). $N$ Engl J Med 1986;314:1465-71.

32 Gibson RS, Boden WE, Theroux P, and the Diltiazem $\overline{\overrightarrow{0}}$ Reinfarction Study Group. Diltiazem and reinfarc- $\frac{3}{3}$ tion in patients with non- $Q$ wave myocardial infarc- tion: results of a double-blind, randomized trial. $N$ 응 Engl J Med 1986;315:423-9.

33 Ouyang P, Bulkley BH, Mellits ED, et al. A doubleblind randomized trial of nifedipine in post-infarction $\frac{\cong}{7}$ unstable angina. Prac Cardiol 1983;3:30-8.

34 Beta Blocker Heart Attack Trial Research Group. A 3 . randomized trial of propranolol in patients with acute $\dot{\delta}$ myocardial infarction: I. Mortality results. $J A M A$ 1982;247:1707-14.

35 The Norwegian Multicenter Study Group. Timolol- $\stackrel{\bigcirc}{\triangle}$ induced reduction in mortality and reinfarction in $\frac{D}{0}$ patients surviving acute myocardial infarction. $N \cong$. Engl J Med 1981;304:801-7.

36 ISIS-1 Study Group. Randomized trial of intravenous ${ }^{\circ}$ atenolol among 16,027 cases of suspected acute $\sim$ myocardial infarction: ISIS-1. Lancet 1986;ii:57-65. స్ట

37 Flaherty JT, Becker LC, Weiss JL, et al. Results of aO randomized prospective trial of intraaortic balloon counterpulsation and intravenous nitroglycerin in

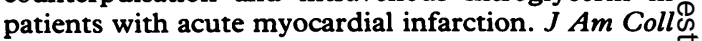
Cardiol 1985;6:434-46.

38 Jugdutt BI, Wortman C, Warnica WJ. Does $\frac{0}{0}$ nitroglycerin therapy in acute myocardial infarction $\frac{\vec{\Phi}}{\circ}$ reduce the incidence of infarct expansion? [Abstract]. $\frac{?}{8}$ J Am Coll Cardiol 1985;5:447.

39 Pfeffer JM, Pfeffer MA, Braunwald E. Influence of chronic captopril therapy on the infarcted left ventricle of the rat. Circ Res 1985;57:84-95.

40 Braunwald E, Kloner RA. Myocardial reperfusion: double-edged sword? J Clin Invest 1985;76:1713-9. 